\title{
The teacher curriculum paradigm instrument: testing for factorial validity and invariance across teachers embracing three different types of paradigm
}

\begin{abstract}
The main purposes of this study were: (a) to test for the factorial validity of the Teacher Curriculum Paradigm Instrument (TCP-I) separately for teachers who embraced standardized management paradigm $(\mathrm{N}=559)$ constructivist best practices paradigm $(\mathrm{N}=293)$, and curriculum wisdom paradigm $(\mathrm{N}=237)$, (b) to cross-validate this structure across and independent sample for the three groups of teachers; and (c) to test for the equivalence of item measurement and theoretical structure across these three types of paradigm. The threefactor structure TCP measurement model was significantly supported by the invariance findings across the three groups of teachers. This had served as the robust and psychometric evidences for the generalizability of the TCP-I in general and dependent on members of the teacher curriculum paradigm in particular.
\end{abstract}

Keyword: Multiple-group analysis; Invariance testing; Teacher curriculum paradigm instrument; Cross-validate; Malaysian teacher; Types of teacher curriculum paradigm 